\title{
Vascular anomaly - persistent left superior vena cava
}

\author{
Vladimir Boshkov*, Lidija Poposka, llina Danilovska \\ University Clinic of Cardiology, Skopje, Republic of Macedonia
}

Persistent left superior vena cava (PLSVC) is a very rare congenital vascular anomaly, $0,3 \%$ in general population. In $90 \%$ of cases PLSVC flows into the right atrium via the coronary sinus, but it can also be associated with other cardiovascular abnormalities including ASD, VSD, bicuspid aortic valve, coarctation of aorta and cor triatriatum, resulting in a right to left sided shunt.

Our case, a 72-old male, was admitted to the hospital for a third replacement of the pacemaker. We didn't have any information for any vascular anomaly. The first indication for implantation of a pacemaker - AAl, was dysfunction of sinoatrial node. Few years later, there was progression of the block and the patient was implanted a new system on the other side, a dual-chamber pacemaker (DDDR). During the second re-implantation, the patient was implanted a singlechamber pacemaker (VVIR). Now we noticed malfunction of the system and high impedance of electrode. X-ray before procedure found lead fracture, hence it was decided to implant a new system on the left side and the left subclavia vein was used as a vascular access. Due to contrast application, an aberrant flow was noticed, i.e. the left subclavia vein drained into the right atrium via the coronary sinus, and active fixation was used. Before each intervention we shall review the complete patient documentation in detail and in case we suspect any anomaly we shall carry out an echocardiography. The dilatation of the coronary sinus would indicate PLSVC.

KEYWORDS: persistent left superior vena cava, cardiac pacing, congenital vascular anomaly.

CITATION: Cardiol Croat. 2013;8(9):301.

Received: $15^{\text {th }}$ Jul 2013

*Address for correspondence: University Clinic of Cardiology, Clinical Center "Mother Theresa", Vodnjanska 17, 1000 Skopje, Republic of Macedonia.

Phone +389 72231132

E-mail: boskov@hotmail.com

\section{Literature}

1. Meijboom W, Vanderheyden M. Biventricular pacing and persistent left superior vena cava. Case report and review of the literature. Acta Cardiol. 2002;57(4):287-90. 